\title{
Awareness, knowledge and comfort of pharmacy students on pre-exposure prophylaxis (PrEP) and post-exposure prophylaxis (PEP) for HIV prevention
}

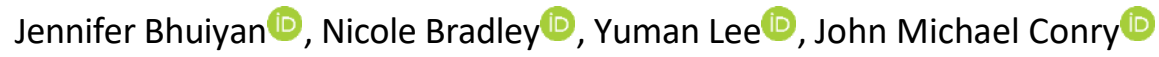 \\ St. John's University, College of Pharmacy and Health Sciences, New York, United States
}

\author{
Keywords \\ Awareness \\ Comfort \\ Knowledge \\ Pharmacy student \\ Post Exposure Prophylaxis (PEP) \\ Pre-Exposure Prophylaxis (PrEP) \\ Correspondence \\ Jennifer Bhuiyan \\ Department of Clinical Health Professions \\ St. John's University \\ College of Pharmacy and Health Sciences \\ 8000 Utopia Parkway Queens \\ New York \\ United States \\ bhuiyanj@stjohns.edu
}

\begin{abstract}
Introduction: Pharmacists are uniquely qualified to promote Pre-Exposure Prophylaxis (PrEP) and Post Exposure Prophylaxis (PEP). The objective of this study was to measure pharmacy students' awareness, knowledge, and comfort regarding PrEP and PEP in an urban setting. Methods: A 23-point questionnaire was distributed to pharmacy students between 2 May 2019 and 31 May 2019. Results: Eighty six pharmacy students responded to the survey. Most of them correctly identified FDA-approved regimens for PrEP and PEP. Most students thought that a pharmacist or intern counselling patients on PREP or PEP was beneficial; however, a minority felt confident counselling patients on PrEP or PEP. Students who met criteria for composite knowledge were significantly more likely to report confidence in counselling. Conclusion: Pharmacy students have strong awareness, but limited knowledge and comfort regarding PrEP and PEP. Results from the survey will be used to assess the learning needs of pharmacy students and inform future curricular changes.
\end{abstract}

\begin{abstract}
Introduction
Human Immunodeficiency Virus (HIV) is a serious global health threat. In 2016, there were over 1.2 million HIV positive individuals living in the United States (US), with 37,968 new infections occurring in 2018 (CDC, 2020). Over two-thirds of these new diagnoses were among gay, bisexual and other men who have sex with men (MSM) (CDC, 2020). From 2014 to 2018, HIV diagnoses decreased about $7 \%$ among adults and adolescents in the US (CDC, 2020). Despite this decline, rates of HIV infection continue to rise among some populations. Rates have increased among Black, Hispanic/Latinx, Asian, American Indian/Alaska Native, and Native Hawaiian/Pacific Islander men who have sex with men (CDC, 2020). In New York City, there are an estimated 127,297 individuals currently living with HIV, and over 1,000 new infections occurred in 2018 (NYCDOHMH, 2019). Similar to the rest of the country, there is a
\end{abstract}

disproportionate number of infections occurring in Black and Hispanic/Latinx individuals (NYCDOHMH, 2019).

Pre-Exposure Prophylaxis ( $\mathrm{PrEP}$ ) is a daily antiretroviral regimen to prevent the acquisition of HIV among individuals most at risk. It was FDA-approved in 2012 after data from several clinical trials demonstrated the safety and efficacy of PrEP in MSM (Grant et al., 2010; Grohskopf et al., 2013; Hosek et al., 2013; Molina et al., 2015), heterosexual women and men (Peterson et al., 2007; Baeten et al. 2012; Thigpen et al., 2012; Van Damme et al., 2012; Murnane et al., 2013; Marrazzo et al., 2015) and persons who inject drugs (Choopanya et al., 2013) who were prescribed a fixed-dose combination of tenofovir disoproxil fumarate $300 \mathrm{mg} / \mathrm{emtricitabine}$ $200 \mathrm{mg}$ (Truvada). PrEP has been shown to be up to $92 \%$ effective in reducing the risk of HIV infection from sex among MSM (Grant et al., 2010), up to 90\% effective in 
reducing the risk of HIV infection among heterosexual women and men (Baeten et al., 2012), and up to 74\% effective in reducing the risk of HIV infection among persons who inject drugs who were highly adherent to PrEP (Choopanya et al., 2013). In 2014, the Centers for Disease Control and Prevention (CDC) established the first set of guidelines for clinicians on the safe and effective use of PrEP in at-risk adults and has since provided updates (CDC, 2019). In 2018, the FDA approved the use of PrEP in adolescents weighing at least 35kg (Tanner, 2020). Recently, in 2019, the FDA approved the use of tenofovir alafenamide $25 \mathrm{mg} /$ emtricitabine $200 \mathrm{mg}$ (Descovy) in at-risk adults and adolescents for PrEP to reduce the risk of HIV infection from sex, excluding those who have receptive vaginal sex (FDA, 2019).

Post Exposure Prophylaxis (PEP) is a means of reducing the risk of HIV acquisition after a single, high-risk HIV exposure (CDC, 2016). High-risk exposures include condomless insertive or receptive vaginal or anal sex, percutaneous exposure to blood, or occupational mucous membrane or non-intact skin contact with bodily fluids of a person with HIV or of unknown HIV status (CDC, 2016). Although randomised controlled trials of non-occupational post-exposure prophylaxis (nPEP) and occupational post-exposure prophylaxis (OPEP) have not been conducted for ethical and logistical reasons, data from the case and observational studies in humans and primates support the use of PEP after a high-risk HIV exposure (Young et al., 2007; Bryant et al., 2009; Irvine et al., 2015). A case-control study of OPEP among healthcare workers has shown an 81\% risk reduction in HIV transmission (Cardo et al., 1997). According to the CDC, tenofovir disoproxil fumarate $300 \mathrm{mg} /$ emtricitabine $200 \mathrm{mg}$ (Truvada) plus raltegravir (Isentress) or dolutegravir (Tivicay) are considered a preferred regimen for both nPEP and OPEP. PEP should be administered within 72 hours of the exposure and consists of a 28-day antiretroviral therapy regimen (CDC, 2016).

There are racial/ethnic disparities in PrEP and PEP use among certain populations. Populations at the highest risk of HIV are less likely to utilise PrEP or PEP as a method of HIV prevention. In a 2017 CDC analysis of National HIV Behavioral Surveillance (NHBS), data from 23 urban areas in the US found that Black and Hispanic/Latinx MSM were less aware of PrEP, less likely to have discussed PrEP with a healthcare provider within the past year, and less likely to use PrEP (Kanny et al., 2017). The disparity between white and Black MSM remained even after considering factors such as lack of health insurance or a usual source of healthcare (Kanny et al., 2017). In 2014, a study was conducted to determine characteristics predictive of PEP use as a function of demographics, including age group, orientation, race/ethnicity, and education level among clients at the PEP-LA programme (Beymer et al., 2014). The study showed under-utilisation of PEP by Black and Hispanic/Latinx people (Beymer et al., 2014). Black people made up $8.5 \%$ of the study population but accounted for $16.7 \%$ of total new HIV infections (Beymer et al., 2014). Hispanic/Latinx individuals made up $32.6 \%$ of the study population, but $42.6 \%$ of new HIV infections (Beymer et al., 2014). In contrast, whites made up $46.5 \%$ of the population, but only $30.4 \%$ of new HIV infections (Beymer et al., 2014). These studies underscore the need for additional healthcare professionals, including pharmacists, to improve awareness and utilisation of PrEP and PEP among atrisk populations.

Pharmacists are medication experts and are uniquely qualified to work with patients at risk of HIV infection. Furthermore, pharmacists are highly accessible to the public as they work in community pharmacies and clinics, as well as in institutional settings. Pharmacists have played important roles in the management of HIV infection by counselling patients on appropriate medication use and the importance of medication adherence, ensuring access to medication through insurance coverage or patient assistance programmes, and monitoring patients on HIV medications for efficacy and safety, including drug interactions (Scott et al., 2010; Tseng et al., 2012; Matyanga, 2014). They also provide important drug information for healthcare providers, patients, and the public. Pharmacists provide harm reduction services, including ensuring access to condoms and sterile syringes in community pharmacies (Bratberg, 2017). Recently, community pharmacists have played a larger role in expanding PrEP and PEP access. In October 2019, California became the first state in the US to allow pharmacists to dispense up to a 60-day supply of PrEP and a supply of PEP without a prescription (CA SB-159 §4052, 2019). These laws require that pharmacists ensure that patients meet clinical criteria for treatment eligibility (CA SB-159 $\S 4052,2019)$. This includes conducting HIV testing prior to dispensing, ordering labs for kidney function, and referring patients to a primary care provider for additional PrEP refills as necessary (CA SB-159 §4052, 2019). Oregon and Colorado have passed similar laws that allow pharmacists to dispense both PrEP and PEP without prescriptions (Gregory, 2020). In New York, a standing order allows pharmacists to dispense a sevenday prescription of PEP to eligible patients and refer them to a provider for additional supplies (NYSDOH, 2018).

Pharmacy education on HIV pre-and post-exposure prophylaxis is vital to ensure that future pharmacists are prepared to work with patients at risk for HIV infection. Limited data exist on PEP knowledge and 
attitudes among US pharmacists, and there are no such known studies among pharmacy students. Results from a study published as an abstract of 250 New York City community pharmacists showed that most had prior PEP knowledge and were willing to dispense PEP starter packs using a Collaborative Drug Therapy Management model (Reid et al., 2015). In 2019, Przybyla and colleagues published a study on the awareness, knowledge, and attitudes towards PrEP among pharmacy students at the University of Buffalo School of Pharmacy in Buffalo, New York. The majority of students (91\%) were aware of PrEP, and over half (61\%) were familiar with CDC guidelines on prescribing PrEP (Przybyla et al., 2019). Increased PrEP knowledge, attitudes and familiarity with these guidelines were associated with confidence in counselling on PrEP (Przybyla et al., 2019). Despite these findings, this study was solely focused on PrEP, did not assess pharmacy students' beliefs, comfort/experience, intent, or value/acceptability regarding $\mathrm{PrEP}$, and was not conducted in an urban/metropolitan region of the US.

There are limited data on pharmacy student awareness, knowledge, beliefs, attitudes, self-efficacy, intent, and norms regarding PrEP and PEP. The objective of this study was to measure pharmacy students' awareness, knowledge, and comfort regarding both PrEP and PEP on an urban college campus. The hypothesis of this study was that pharmacy students have limited awareness, knowledge, and comfort regarding PrEP and PEP.

\section{Methods}

A 23-point questionnaire developed and adapted from a study by Unni and colleagues (Unni et al., 2016) and a validated tool (Legare et al., 2014) were used to measure pharmacy students' knowledge, attitudes, beliefs, self-efficacy, intent, and norms regarding PrEP and PEP use and promotion. The questionnaire was based on the Theory of Planned Behavior (TPB) (Ajzen, 1991), which is the most appropriate theory to predict the clinical practice behaviour of healthcare professionals (Godin et al., 2008).

The questionnaire was distributed as a survey to pharmacy students between 2 May 2019 and 31 May 2019 via Google Forms. Pharmacy students from professional years 1-4 were included in this survey. Completion of the survey was anonymous; respondents were offered an opportunity to enter a raffle as an incentive to participate. This study was reviewed as exempt from approval by the University's Institutional Review Board. Informed consent was obtained from all participants.
Demographic information, baseline knowledge, awareness, beliefs, and attitudes were assessed throughout the survey. Results were analysed and reported using descriptive statistics. Adjusted odds ratios and $95 \%$ confidence intervals were calculated to compare differences in knowledge, comfort, and intention between students in different professional years of the pharmacy programme.

\section{Results \\ Demographics}

There were 86 responses to this survey. As seen in Table I, most of the students were between $18-24$ years old, identified as female, and were Asian or white. Nearly $85 \%$ of students reported working in a pharmacy, with $40.7 \%$ working in community pharmacy chains, $22.1 \%$ working in hospital pharmacies, and $19.8 \%$ working in independent pharmacies.

\section{Table I: Baseline characteristics}

\begin{tabular}{|c|c|}
\hline Description & Number (\%) \\
\hline \multicolumn{2}{|l|}{ Age $(n=81)$} \\
\hline$<18$ & 0 \\
\hline $18-24$ & $80(98.8)$ \\
\hline $24-30$ & $1(1.2)$ \\
\hline$>30$ & 0 \\
\hline \multicolumn{2}{|l|}{ Gender identity $(n=86)$} \\
\hline Female & $66(76.7)$ \\
\hline Male & $19(22.1)$ \\
\hline Prefer not to say & $1(1.2)$ \\
\hline \multicolumn{2}{|l|}{ Race/ethnicity ( $n=86$ ) } \\
\hline \multicolumn{2}{|l|}{ Race } \\
\hline Black/African American & $1(1.2)$ \\
\hline White & $26(30.2)$ \\
\hline Asian & $55(64)$ \\
\hline Native Hawaiian/Pacific Islander & $1(1.2)$ \\
\hline American Indian/Alaska Native & $1(1.2)$ \\
\hline Other & $5(6)$ \\
\hline \multicolumn{2}{|l|}{ Ethnicity } \\
\hline Hispanic/Latinx & $2(2.4)$ \\
\hline Not Hispanic/Latinx & $83(97.6)$ \\
\hline \multicolumn{2}{|l|}{ Work Experience $(n=86)$} \\
\hline Community pharmacy & $52(60.5)$ \\
\hline Independent & $17(19.8)$ \\
\hline Chain & $35(40.7)$ \\
\hline Hospital & $19(22.1)$ \\
\hline Hospital and community pharmacy & $2(2.4)$ \\
\hline None & $13(15.1)$ \\
\hline \multicolumn{2}{|l|}{ Year in pharmacy program $(n=86)$} \\
\hline P1 & $13(15.1)$ \\
\hline $\mathrm{P} 2$ & $23(26.7)$ \\
\hline P3 & $27(31.4)$ \\
\hline P4 & $23(26.7)$ \\
\hline \multicolumn{2}{|l|}{ Course experience $(n=86)$} \\
\hline Infectious diseases drugs \& diseases & $64(74.4)$ \\
\hline HIV elective & $22(25.6)$ \\
\hline Infectious diseases elective & $14(16.3)$ \\
\hline
\end{tabular}


Approximately $15 \%$ of students were in their first professional year (P1), 27\% in their second professional year (P2), 31\% in their third professional year (P3), and $27 \%$ in their fourth professional year (P4). Nearly $75 \%$ of students identified as having at least one course covering material on PrEP and PEP, $24.4 \%$ had at least two courses, and $5.8 \%$ had at least three courses. Complete responses to the survey can be found in Table II.

Table II: Survey responses

\begin{tabular}{|c|c|}
\hline Description & $\begin{array}{c}\text { Number } \\
(\%)\end{array}$ \\
\hline \multicolumn{2}{|l|}{$\begin{array}{l}\text { Which of the following are high-risk } \\
\text { exposures/behaviours (select all that apply)? } \\
\text { ( } n=86)\end{array}$} \\
\hline Contact with urine or saliva & $18(20.9)$ \\
\hline Contact with blood, semen, or breastmilk & $86(100)$ \\
\hline Contact with contaminated surface & $18(20.9)$ \\
\hline \multicolumn{2}{|l|}{$\begin{array}{l}\text { Which of the following methods can be utilised for } \\
\text { the prevention of HIV infection (select all that } \\
\text { apply)? ( } n=86 \text { ) }\end{array}$} \\
\hline Condom & $84(97.7)$ \\
\hline Sterile needle use & $81(94.2)$ \\
\hline Chemoprophylaxis & $39(45.3)$ \\
\hline Avoidance of high-risk behaviours & $85(98.8)$ \\
\hline \multicolumn{2}{|l|}{$\begin{array}{l}\text { Do you know what "Pre-Exposure Prophylaxis } \\
\text { (PrEP) is?" }\end{array}$} \\
\hline 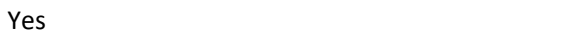 & $74(86)$ \\
\hline No & $12(14)$ \\
\hline \multicolumn{2}{|l|}{ Have you ever heard of PrEP/PEP? } \\
\hline \multicolumn{2}{|l|}{$\operatorname{PrEP}(n=85)$} \\
\hline Yes & $76(89.4)$ \\
\hline No & $9(10.6)$ \\
\hline \multicolumn{2}{|l|}{$\operatorname{PEP}(n=86)$} \\
\hline Yes & $75(87.2)$ \\
\hline No & $11(12.8)$ \\
\hline \multicolumn{2}{|l|}{ Do you know what PrEP/PEP is? } \\
\hline \multicolumn{2}{|l|}{$\operatorname{PrEP}(n=86)$} \\
\hline Yes & $74(86)$ \\
\hline No & $12(14)$ \\
\hline \multicolumn{2}{|l|}{$\operatorname{PEP}(n=86)$} \\
\hline Yes & 73 (84.9) \\
\hline No & $13(15.1)$ \\
\hline \multicolumn{2}{|l|}{$\begin{array}{l}\text { What is the recommended duration of therapy of } \\
\text { PrEP/PEP? }\end{array}$} \\
\hline \multicolumn{2}{|l|}{$\operatorname{PrEP}(n=86)$} \\
\hline For as long as risk of acquisition is present & $45(52.3)$ \\
\hline Indefinite & $6(7.0)$ \\
\hline 7 days & $13(15.1)$ \\
\hline 30 days & $11(12.8)$ \\
\hline I don't know & $11(12.8)$ \\
\hline \multicolumn{2}{|l|}{$\operatorname{PEP}(n=85)$} \\
\hline For as long as risk of acquisition is present & $11(12.9)$ \\
\hline Indefinite & $7(8.2)$ \\
\hline 7 days & $10(11.8)$ \\
\hline 28 days & $57(67.1)$ \\
\hline \multicolumn{2}{|l|}{$\begin{array}{l}\text { Which of the following regimens is FDA-approved } \\
\text { for PrEP/ a guideline recommended regimen for }\end{array}$} \\
\hline \multicolumn{2}{|l|}{ PEP? } \\
\hline \multicolumn{2}{|l|}{$\operatorname{PrEP}(n=84)$} \\
\hline $\begin{array}{l}\text { Truvada (tenofovir disoproxil } \\
\text { fumarate/emtricitabine) }\end{array}$ & 75 (89.3) \\
\hline Descovy (tenofovir alafenamide/emtricitabine) & $2(2.4)$ \\
\hline
\end{tabular}

\begin{tabular}{|c|c|}
\hline Description & $\begin{array}{c}\text { Number } \\
(\%)\end{array}$ \\
\hline $\begin{array}{l}\text { Atripla (tenofovir disoproxil } \\
\text { fumarate/emtricitabine + efavirenz) }\end{array}$ & $7(8.3)$ \\
\hline \multicolumn{2}{|l|}{$\operatorname{PEP}(n=84)$} \\
\hline $\begin{array}{l}\text { Truvada (tenofovir disoproxil } \\
\text { fumarate/emtricitabine) }\end{array}$ & $8(9.5)$ \\
\hline $\begin{array}{l}\text { Atripla (tenofovir disoproxil } \\
\text { fumarate/emtricitabine + efavirenz) + Sustiva } \\
\text { (efavirenz) }\end{array}$ & $10(11.9)$ \\
\hline $\begin{array}{l}\text { Truvada (tenofovir disoproxil } \\
\text { fumarate/emtricitabine) } \\
+ \text { Isentress (raltegravir) }\end{array}$ & $45(53.6)$ \\
\hline $\begin{array}{l}\text { Truvada (tenofovir disoproxil } \\
\text { fumarate/emtricitabine) } \\
+ \text { Tivicay (dolutegravir) }\end{array}$ & $21(25)$ \\
\hline \multicolumn{2}{|l|}{ Do you know where to get PrEP/PEP? } \\
\hline \multicolumn{2}{|l|}{$\operatorname{PrEP}(n=86)$} \\
\hline Yes & $49(57.0)$ \\
\hline No & $37(43.0)$ \\
\hline \multicolumn{2}{|l|}{$\operatorname{PEP}(n=85)$} \\
\hline Yes & $47(55.3)$ \\
\hline No & $28(44.7)$ \\
\hline \multicolumn{2}{|l|}{ Have you seen PrEP/PEP? } \\
\hline \multicolumn{2}{|l|}{$\operatorname{PrEP}(n=86)$} \\
\hline Yes & $43(50)$ \\
\hline No & $43(50)$ \\
\hline \multicolumn{2}{|l|}{$\operatorname{PEP}(n=85)$} \\
\hline Yes & $29(34.1)$ \\
\hline No & 56 (65.9) \\
\hline \multicolumn{2}{|l|}{ Do you know how much PrEP/PEP costs? } \\
\hline \multicolumn{2}{|l|}{$\operatorname{PrEP}(n=86)$} \\
\hline Yes & $21(24.4)$ \\
\hline No & $65(75.6)$ \\
\hline \multicolumn{2}{|l|}{$\operatorname{PEP}(n=85)$} \\
\hline Yes & $21(24.7)$ \\
\hline No & $64(75.3)$ \\
\hline \multicolumn{2}{|l|}{ Have you ever counselled a patient on PrEP/PEP? } \\
\hline \multicolumn{2}{|l|}{$\operatorname{PrEP}(n=86)$} \\
\hline Yes & $11(12.8)$ \\
\hline No & $75(87.2)$ \\
\hline \multicolumn{2}{|l|}{$\operatorname{PEP}(n=85)$} \\
\hline Yes & $6(7.1)$ \\
\hline No & 79 (97.9) \\
\hline
\end{tabular}

\section{Knowledge}

All students were able to correctly identify contact with blood, semen, or breast milk as high-risk exposures/behaviours for the transmission of HIV. Approximately $20 \%$ of students incorrectly selected contact with urine or saliva or contact with a contaminated surface as high-risk exposures/behaviours for virus transmission. Of the students who incorrectly identified high-risk exposures/behaviours, $19.2 \%$ were $\mathrm{P} 1,26.9 \%$ were $\mathrm{P} 2,30.8 \%$ were $\mathrm{P} 3$, and $26.9 \%$ were $\mathrm{P} 4$.

When asked about methods to prevent HIV infection, $100 \%$ of students were able to identify at least one method of prevention (condom use, sterile needle use, chemoprophylaxis, or avoidance of high-risk behaviours), $7 \%$ identified two methods of prevention (condom use and avoidance of high-risk behaviours or sterile needle use and avoidance of high-risk behaviours), $46.5 \%$ 
identified three methods of prevention (condom use, sterile needle use, and avoidance of high-risk behaviours), and $45.3 \%$ of students identified four methods of prevention (condom use, sterile needle use, avoidance of high-risk behaviours, and chemoprophylaxis). Most students who were able to identify chemoprophylaxis as a means of prevention were in their P2 (34.2\%) or P3 (34.2\%) years.

About $86 \%$ of students reported that they knew what PrEP was. $75 \%$ of students who did not know what PrEP was were in their $\mathrm{P} 1$ year. At the time that the survey was distributed, the only FDA-approved regimen for PrEP was tenofovir disoproxil fumarate/emtricitabine (Truvada). Approximately $90 \%$ of students correctly identified this as an FDA-approved regimen for PrEP. Among those who did not correctly identify this regimen, $66.7 \%$ were $\mathrm{P} 1$ students, $22.2 \%$ were $\mathrm{P} 2$, and $1.1 \%$ were P3. All P4 students were able to identify tenofovir disoproxil fumarate/emtricitabine (Truvada) as an FDA-approved regimen for PrEP. About half $(52.3 \%)$ of the students correctly identified the appropriate duration for PrEP treatment. Among those who were unable to identify the recommended duration for PrEP treatment, $21.9 \%$ were P1 students, $29.3 \%$ were $P 2,31.7 \%$ were $P 3$, and $17.1 \%$ were $P 4$. As seen in Table III, there was no observable difference in odds that a student would have greater PrEP knowledge depending on their professional year.

Table III: PrEP and PEP knowledge, comfort, intent stratified by year in programme

\begin{tabular}{|c|c|c|}
\hline & $\begin{array}{c}\text { PrEP } \\
\text { aOR }(95 \% \mathrm{CI})\end{array}$ & $\begin{array}{c}\text { PEP } \\
\text { aOR }(95 \% \mathrm{Cl})\end{array}$ \\
\hline \multicolumn{3}{|l|}{ Knowledge } \\
\hline \multicolumn{3}{|l|}{ Duration } \\
\hline P1 & $0.52(-1.87,1.73)$ & $0.37(-2.19,1.23)$ \\
\hline $\mathrm{P} 2$ & $0.62(-1.45,1.61)$ & $0.20(-2.6,0.56)$ \\
\hline P3 & $0.97(-0.94,2.42)$ & $3.02(0.003,9.075)$ \\
\hline P4 & $2.69(-0.03,7.41)$ & $4.68(0.23,17.42)$ \\
\hline \multicolumn{3}{|c|}{ Recommended regimen } \\
\hline P1 & $0.09(-3.88,0.35)$ & $0.63(-1.76,2.32)$ \\
\hline $\mathrm{P} 2$ & $0.50(-2.04,1.99)$ & $0.24(-2.47,0.71)$ \\
\hline P3 & $5.31(-0.44,43.76)$ & $3.24(-0.15,12,19)$ \\
\hline P4 & $9.73(-0.60,172.71)$ & $2.46(-0.43,9.36)$ \\
\hline \multicolumn{3}{|l|}{ Comfort } \\
\hline \multicolumn{3}{|c|}{$\overline{\text { Confidence counseling }}$} \\
\hline P1 & $0.07(0.01,1.15)$ & $0.17(0.02,1.39)$ \\
\hline $\mathrm{P} 2$ & $0.14(0.03,0.67)$ & $0.03(0.002,0.57)$ \\
\hline P3 & $3.81(1.44,10.09)$ & $6.13(2.21,16.97)$ \\
\hline P4 & $2.69(1.00,7.29)$ & $1.89(0.69,5.19)$ \\
\hline \multicolumn{3}{|c|}{ Difficulty counseling } \\
\hline P1 & $2.17(0.65,7.27)$ & $2.29(0.68,7.70)$ \\
\hline $\mathrm{P} 2$ & $5.28(1.82,15.3)$ & $4.26(1.52,11.91)$ \\
\hline P3 & $0.38(0.14,1.00)$ & $0.32(0.12,0.86)$ \\
\hline P4 & $0.32(0.11,0.92)$ & $0.45(0.16,1.25)$ \\
\hline \multicolumn{3}{|c|}{ Experience counseling } \\
\hline P1 & $0.22(-4.43,3.92)$ & $0.43(-3.79,8.17)$ \\
\hline $\mathrm{P} 2$ & $0.10(-5.15,1.82)$ & $0.21(-4.50,3.85)$ \\
\hline P3 & $0.79(-1.63,3.27)$ & $1.1(-1.6,6.4)$ \\
\hline P4 & $10.67(0.92,45.13)$ & $6.42(0.09,37.84)$ \\
\hline \multicolumn{3}{|l|}{ Intent } \\
\hline \multicolumn{3}{|c|}{$\overline{\text { Intent to counsel }}$} \\
\hline P1 & $0.20(-2.96,0.75)$ & $0.41(-2.24,1.55)$ \\
\hline $\mathrm{P} 2$ & $0.52(-1.88,1.81)$ & $0.64(-1.65,2.14)$ \\
\hline P3 & $15.26(-0.14,267.64)$ & $18.8(0.08,328.42)$ \\
\hline P4 & $1.26(-1.16,5.04)$ & $0.48(-1.90,1.55)$ \\
\hline \multicolumn{3}{|c|}{ Acceptability of counselling } \\
\hline P1 & $1.51(-2.59,30.25)$ & $3.2(-1.76,59.25)$ \\
\hline $\mathrm{P} 2$ & $0.34(-3.09,2.60)$ & $0.32(-2.61,1.41)$ \\
\hline P3 & $3.93(-1.61,77.00)$ & $3.5(-0.89,29.97)$ \\
\hline P4 & $0.34(-3.09,2.60)$ & $0.57(-2.07,2.62)$ \\
\hline \multicolumn{3}{|c|}{ Benefit of counselling } \\
\hline P1 & $0.34(-3.56,4.03)$ & $0.24(-3.34,1.57)$ \\
\hline $\mathrm{P} 2$ & $0.72(-2.78,8.35)$ & $0.53(-2.5-, 3.36)$ \\
\hline P3 & $0.91(-2.54,10.52)$ & $1.89(-1.60,17.7)$ \\
\hline P4 & $2.3(-2.20,47.71)$ & $3.97(-1.57,75.54)$ \\
\hline
\end{tabular}

aOR= adjusted Odds Ratio; $\mathrm{Cl}=$ Confidence interval; $p<0.05$; Approximate area for inclusion: Results - knowledge 
Approximately $85 \%$ reported that they knew what PEP was. Students in their P1 or P2 year accounted for 90.9\% of the respondents who had not heard of PEP or who did not know what PEP was. Approximately $79 \%$ of students identified either tenofovir disoproxil fumarate $300 \mathrm{mg} /$ emtricitabine 200mg (Truvada) plus raltegravir (Isentress) or dolutegravir (Tivicay) as CDC recommended regimens for PEP. A 28-day recommended duration of PEP therapy was correctly identified by $67.1 \%$ of students. Of those who were unable to identify the appropriate duration of PEP, $24.1 \%$ were P1 students, $48.3 \%$ were $\mathrm{P} 2,17.2 \%$ were $\mathrm{P} 3$, and $10.3 \%$ were $\mathrm{P} 4$. The majority of respondents (78.6\%) were able to correctly identify a preferred regimen for PEP. $50 \%$ of the students who incorrectly identified a preferred regimen for PEP were in their P2 year. Despite this, there was no observable difference in odds that a student would have greater PEP knowledge depending on their professional year.

As seen in Table IV, students who met the criteria for composite knowledge (knowledge of three or more methods for HIV prevention, risk factors, and recommended treatment regimens) were significantly more likely to report confidence in counselling on PrEP (aOR 10.95; 95\% Cl $[1.3,32.61]$ ) and PEP (aOR 8.20; 95\% $\mathrm{Cl}[1.03,24.02])$.

Table IV: Factors associated with confidence in PrEP/PEP counselling

\begin{tabular}{lcc}
\hline & $\begin{array}{c}\text { PrEP } \\
\text { aOR (95\% CI) }\end{array}$ & $\begin{array}{c}\text { PEP } \\
\text { aOR (95\% CI) }\end{array}$ \\
\hline $\begin{array}{l}\text { Knowledge of three or more methods of HIV } \\
\text { prevention }\end{array}$ & $7.27(-0.92,132.98)$ & $2.62(-1.21,22.94)$ \\
Knowledge of risk factors & $2.72(-0.33,10.37)$ & $2.39(-0.47,9.13)$ \\
Knowledge of recommended treatment & $12.38(-0.36,218.94)$ & $4.81(0.03,22.59)$ \\
regimen & & \\
Knowledge of treatment duration & $5.10(0.58,14.52)$ & $9.13(0.68,42.21)$ \\
Composite knowledge (three+ prevention, & $10.95(1.3,32.61)$ & $8.20(1.03,24.02)$ \\
correct risk factors, regimen \& duration) & & \\
Year in the pharmacy programme & & \\
$\quad$ P1 & $0.07(0.01,1.15)$ & $0.17(0.02,1.39)$ \\
$\quad$ P2 & $0.14(0.03,0.67)$ & $0.03(0.002,0.57)$ \\
P3 & $3.81(1.44,10.09)$ & $6.13(2.21,16.97)$ \\
P4 & $2.69(1.00,7.29)$ & $1.89(0.69,5.19)$ \\
Work experience in community pharmacy & $2.76(-0.03,7.82)$ & $1.38(-0.66,3.69)$ \\
\hline
\end{tabular}

Approximate area for inclusion: Results - knowledge

\section{Awareness}

Approximately $90 \%$ of students had heard of PrEP. About $43 \%$ of students did not know where to obtain PrEP, half (50\%) had not seen PrEP, and three-quarters of students $(75.6 \%)$ did not know the cost of PrEP. No significant difference in awareness was found when stratified by type of pharmacy work experience.

$87 \%$ of students had heard of PEP. However, almost half of the students (44.7\%) did not know where to get PEP, 75.3\% did not know how much PEP costs, and $65.9 \%$ had never seen PEP before. No significant difference in awareness was found when stratified by type of pharmacy work experience.

\section{Comfort/experience}

About $90 \%$ of students reported that they had never counselled a patient on PrEP. One half (51.2\%) of students reported they did not confidently feel that they could counsel patients on PrEP, and the other half (45.4\%) reported that counselling patients on PrEP would be difficult or extremely difficult. Although P4 students accounted for the majority of those who reported previously counselling a patient on PrEP (72.7\%), no significant differences in prior counselling experience were observed depending on the programme year. Significantly more P3 (aOR 3.81, Cl $1.44,10.09$ ) and P4 students (aOR 2.69, Cl 1.00, 7.29) were confident in counselling a patient on PrEP. P2 students were more likely to find counselling on PrEP to be difficult or extremely difficult (aOR 5.28, $\mathrm{Cl} 1.82$, 15.3) compared to other students.

Similarly, $92.9 \%$ of students never counselled a patient on PEP, $71 \%$ lacked the confidence to do so, and $44.7 \%$ stated that counselling patients on PEP would be difficult or extremely difficult for them. There were no significant differences in experience counselling depending on the year of programme, though P4 students accounted for the highest percentage of those who have counselled a patient on PEP (66.6\%). Significantly more P3 students (aOR 6.13, Cl 2.21, 16.97) were confident in counselling a patient on PEP. Again, P2 students were more likely to find counselling on PEP to be difficult or extremely difficult (aOR 4.26, Cl 1.52, 11.91) compared to other students. 


\section{Intent}

Approximately $85 \%$ of students reported that they intend to counsel patients on PrEP and $81 \%$ on PEP. No significant differences in intent to counsel on PrEP or PEP depending on the programme year were found.

\section{Value/acceptability}

As depicted in Figure 1, approximately $95 \%$ of students agreed or strongly agreed that it would be acceptable to counsel patients on PrEP. A majority of students (68.6\%) agreed or strongly agreed that most of the people who were important to them within the pharmacy profession would counsel patients on PrEP or PEP. Additionally, $96 \%$ of students thought that a

\section{I am confident that I could counsel patients on PrEP therapy \\ I am confident that I could counsel patients on PEP therapy \\ It would be acceptable to counsel patients about PrEP therapy \\ It would be acceptable to counsel patients about PEP therapy}

Most persons who are important to me in the profession would counsel patients on PrEP

Most persons who are important to me in the profession would counsel patients on PEP

I intent to counsel patients on PrEP

I intent to counsel patients on PEP

$$
\text { Strongly Disagree Disagree }
$$$$
\text { Iintent to counsel patients on PEP }
$$$$
\text { - Neutin }
$$

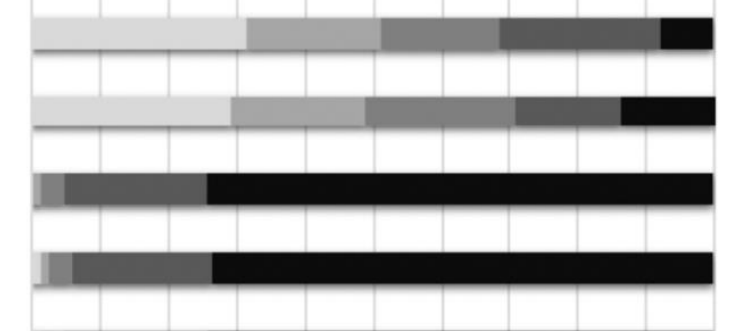
beneficial. No significant differences in the acceptability of counselling or the perceived benefit of PrEP counselling depending on the year of the programme were found.

With regards to $P E P, 90 \%$ of students agreed or strongly agreed that it would be acceptable to counsel patients, $72 \%$ agreed or strongly agreed that most of the people who were important to them within the pharmacy profession would counsel patients, and $96.4 \%$ felt that PEP counselling would be beneficial. No significant differences in the acceptability of counselling or the perceived benefit of counselling on PEP depending on the year of the programme were found.

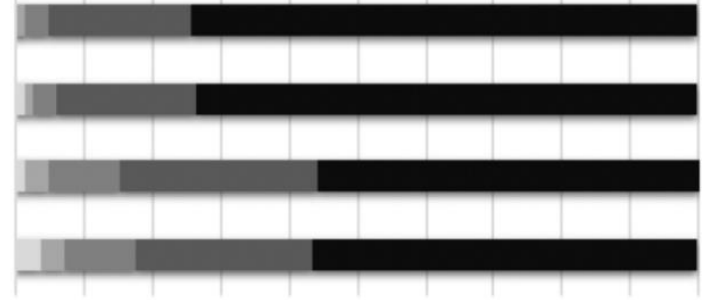

$\begin{array}{lllllllllll}0 \% & 10 \% & 20 \% & 30 \% & 40 \% & 50 \% & 60 \% & 70 \% & 80 \% & 90 \% & 100 \%\end{array}$

Agree $\quad$ Strongly Agree

Approximate area for inclusion: Results - value/acceptability

Figure 1: Student perceptions of PrEP and PEP counselling (\%)

\section{Discussion}

To the best of the authors' knowledge, this is the first published study to measure the knowledge, awareness and comfort of pharmacy students regarding PrEP and PEP on an urban college campus. Pharmacy students have strong awareness but limited knowledge and comfort regarding PrEP and PEP. Despite these limitations, the majority of students have a strong intent to counsel patients on PrEP or PEP and think that counselling patients on PrEP or PEP are beneficial. These findings have significant implications for curricular changes and can help identify the learning needs of current pharmacy students in order to better prepare them to fulfil the expanding role of pharmacists in PrEP and PEP management.

\section{Knowledge}

Responses to the survey highlight knowledge deficits in HIV transmission and prevention methods. While most pharmacy students knew what PrEP and PEP were, less than half of the students surveyed correctly identified chemoprophylaxis as a method of HIV prevention. Deficits were present across all years of education but were most evident in P1 and P2 students. Students who met the criteria for composite knowledge were significantly more likely to report confidence in counselling on PrEP (aOR 10.95; 95\% Cl [1.3, 32.61]) 
and PEP (aOR 8.20; 95\% $\mathrm{Cl}[1.03,24.02])$. This finding of PrEP and PEP knowledge as a correlate of confidence is consistent with findings from a previous study among pharmacy students, which found that greater PrEP knowledge was significantly associated with confidence in PrEP counselling (Przybyla et al., 2019). This study also found that familiarity with CDC PrEP guidelines was significantly associated with intent to counsel patients on PrEP (Przybyla et al., 2019). Similarly, a previous study among prescribers showed a positive association between PrEP knowledge and past and future rates of PrEP prescribing as well as future intent to prescribe PrEP (Blumenthal et al., 2015). These findings suggest that additional education/training is warranted in HIV transmission and prevention methods among pharmacy students across all professional years to improve their knowledge, confidence and intention to counsel regarding PrEP and PEP.

\section{Awareness}

The majority of pharmacy students had heard of PrEP and PEP, but few knew about how to access them or how much they cost. Interestingly, no difference in awareness related to access of PrEP or PEP was found based on the type of work experience, including community pharmacy practice, where PrEP and PEP are commonly dispensed. This lack of awareness regarding PrEP and PEP access among pharmacy students is especially concerning as about half of the students reported working in community pharmacies. However, only 50\% reported they had seen PrEP, and 34\% reported they had seen PEP, suggesting there may be barriers to utilisation, prescribing or dispensing of PrEP (Broekhuis et al., 2018) or PEP (Reid et al., 2014). In the US, insurance coverage and the cost of PrEP have been identified as significant barriers to PrEP utilisation for patients and prescribing by providers (Patel et al., 2017). Pharmacy students should be aware of these barriers to PrEP uptake and prescribing, as well as resources available to patients that will cover the costs of PrEP. While the majority of insurance plans and Medicaid programmes cover PrEP, prior authorisations may be required (CDC, 2020). Additional resources include local, state, and federal resources for payment assistance, such as pharmaceutical company/foundation patient assistance programmes (Gilead, 2020), 340B programmes which offer PrEP/PEP at free or reduced cost (NASTAD, 2018), and the recently implemented Ready, Set PrEP nationwide programme by the US Department of Health and Human Services, which offers free PrEP to individuals without insurance (DHHS, 2020).

\section{Comfort/experience}

Pharmacy students have limited experience counselling patients on PrEP and PEP; only $13 \%$ of students reported having ever counselled patients on PrEP and $7 \%$ on PEP. This suggests the need to incorporate learning opportunities on counselling for pharmacy students on PrEP and PEP via simulated experiences and/or experiential learning. Students' limited experience counselling on PrEP or PEP may also reflect poor PrEP and PEP utilisation due to pharmacy barriers to dispensing PEP, or missed opportunities to engage pharmacy students in counselling patients on these regimens at their workplaces. A minority of students in this study reported that counselling patients on PrEP or PEP would be easy. P2 students were more likely to express difficulty in counselling patients on PrEP (aOR $5.28,95 \% \mathrm{Cl}[1.82,15.3])$ and PEP (aOR 4.26 [1.52, 11.91]) than students from other professional years. A possible explanation for this is the lack of exposure to/experience in counselling among P2 students than students in P3 and P4 years since NYS pharmacy law only permits pharmacy interns to counsel patients (under the supervision of a licensed pharmacist) in their P3 year (NYSED, 2017). It is unclear why P1 students, who are junior to P2 students in their pharmacy training, did not express a level of difficulty in counselling patients that was consistent with or even exceeded that of P2 students.

\section{Intent, Value and Acceptability}

Despite their low reported confidence, self-efficacy, and limited reported experience in counselling patients on PrEP and PEP, most pharmacy students strongly agreed or agreed with the statement, "I intend to counsel patients on PrEP/PEP." Pharmacy students appear to value prophylaxis and the role of the pharmacist in counselling patients on these HIV prevention methods. The majority of respondents reported that they think a pharmacist or intern counselling patients on PrEP or PEP would be beneficial and that counselling patients about their PrEP or PEP would be acceptable. No significant differences in intent, acceptability, or benefit were found across pharmacy students of all years. The strong intent, acceptability and perceived benefit of counselling patients on prophylaxis are noteworthy given the stigma associated with HIV and populations at-risk for infection (CDC, 2020). Students may also recognise the important role of pharmacists in PrEP and PEP adherence and counselling and HIV prevention at large (Matyanga, 2014; Unni et al., 2016; Broekhius et al., 2018). 
The high level of awareness regarding PrEP and PEP ( $90 \%$ and $87 \%$, respectively) demonstrated among pharmacy students in this study is consistent with findings from Przybyla and colleagues (2016), which found that $91 \%$ of pharmacy students at the University of Buffalo were aware of PrEP. Additionally, 51\% identified an appropriate medication regimen for PrEP, $55 \%$ identified the correct dosing frequency, and $64 \%$ of students reported they were confident that they could counsel patients about PrEP (Przybyla et al., 2016). In this study, a higher percentage of students surveyed identified appropriate medication regimens for PrEP and PEP (90\% and 78.6\%, respectively) and just over half identified the correct duration of therapy for PrEP and PEP (52.3\% and 67\%, respectively). The 64\% of pharmacy students who reported they were confident that they could counsel patients about PrEP in the study by Przybyla and colleagues (2016) was slightly higher than the $49 \%$ in this study. Despite these differences, the overwhelming majority of students in both studies ( 81 to $87 \%$ ) replied that they intend to counsel patients on PrEP and PEP.

Compared to pharmacists, pharmacy students have similar knowledge about PrEP and PEP regimens but greater confidence and intent regarding PrEP and PEP utilisation. In a study by Unni and colleagues (2016), which examined perceptions and knowledge about PrEP among 251 Midwestern US community pharmacists, about half (46.6\%) identified tenofovir/emtricitabine as a medication that can be used for PrEP, and over half (57.7\%) disagreed or strongly disagreed that they knew which medications are used in PrEP. Only about $17 \%$ of pharmacists reported that they intended to counsel patients on PrEP, and about 20\% agreed that they either had the ability to counsel patients on PrEP or were confident that they could counsel patients on PrEP (Unni et al., 2016). In comparison, over half of the pharmacy students in this study identified appropriate regimens for PrEP and PEP (52.3\% and 67.1\%, respectively). Additionally, a higher percentage of pharmacy students in this study reported that they intended to counsel patients on PrEP or PEP ( $85 \%$ and $81 \%$, respectively), which is consistent with a previous study indicating pharmacy students' high intention to counsel patients about PrEP (Przybyla et al., 2019). Pharmacy students in this study also reported higher levels of confidence regarding counselling patients on PrEP and PEP (48.8\% and $29 \%$, respectively).

A study of 250 pharmacists in New York City indicated that about $75 \%$ of pharmacists had prior knowledge about PEP, and $81 \%$ of pharmacists were somewhat or very willing to dispense PEP starter packs through Collaborative Drug Therapy Monitoring (CDTM) (Reid et al., 2015). Willingness to prescribe PEP did not significantly differ across factors such as prior PEP or CDTM knowledge (Reid et al., 2015). Major barriers to dispensing PEP using CDTM included discomfort dispensing PEP without a physician-issued prescription, lack of a separate private space within the pharmacy, discomfort asking screening questions, and lack of time to conduct CDTM (Reid et al., 2015). Education and training on PEP and CDTM were identified as key components to address these barriers (Reid et al., 2015). These barriers may explain why less than half of pharmacy students in this survey reported having seen PEP or having experience in counselling patients on PEP.

\section{Strengths and limitations}

This study has several limitations. The survey was disseminated toward the end of the semester, which may have led to limited responses from students. The study was conducted at only one pharmacy school, and findings cannot be generalised to pharmacy students at other institutions or geographic areas. A strength of this study was that it investigated the knowledge, attitudes and comfort of pharmacy students related to both PrEP and PEP. Additionally, this study utilised cognitive behaviour theory, including a validated tool, to inform the development of its questionnaire (Legare et al., 2014).

\section{Future directions}

Additional qualitative studies regarding beliefs, perceptions of PrEP and PEP among pharmacy students via focus groups may help explain some of the findings from the study. Also, studies among faculty and pharmacy students across the US may help highlight national gaps and trends in pharmacy education and training experiences related to PrEP and PEP, as well as cultural and institutional barriers to implementing these learning opportunities in pharmacy school curricula.

Pharmacy students have strong awareness but limited knowledge and comfort regarding PrEP and PEP. Results from the survey will be used to assess the learning needs of pharmacy students regarding PrEP and PEP and inform future curricular changes.

\section{References}

Ajzen I. The theory of planned behavior. (1991). Organ Behav and Hum Dec Process., 50(2):179-211. https://doi.org/10.1016/0749-5978(91)90020-T

Baeten JM, Donnell D, Ndase P, et al. (2012). Antiretroviral Prophylaxis for HIV Prevention in Heterosexual Men and 
Women. N Engl J Med.,367(5):399-410.

https://doi.org/10.1056/NEJMoa1108524

Beymer MR, Bolan RK, Flynn RP, et al. (2014). Uptake and repeat use of postexposure prophylaxis in a communitybased clinic in Los Angeles, California. AIDS Res Hum Retroviruses.,30(9):848-855. https://doi.org/10.1089/aid.2014.0017

Blumenthal J, Jain S, Krakower D, et al. (2015). Knowledge is Power! Increased Provider Knowledge Scores regarding Preexposure Prophylaxis (PrEP) are Associated with Higher Rates of PrEP Prescription and Future Intent to Prescribe PrEP. AIDS Behav.,19(5):802-810. https://doi.org/10.1007/s10461-015-0996-z

Bratberg JP. Opioids, naloxone, and beyond: The intersection of medication safety, public health, and pharmacy. (2017). J Am Pharm Assoc.,57(2): S5-S7. https://doi.org/10.1016/j.japh.2017.02.006

Broekhuis JM, Scarsi KK, Sayles HR, et al. (2018). Midwest pharmacists' familiarity, experience, and willingness to provide pre-exposure prophylaxis (PrEP) for HIV. PLoS ONE. 13(11):e0207372.

https://doi.org/10.1371/journal.pone.0207372

Bryant J, Baxter L, Hird S. (2009). Non-occupational postexposure prophylaxis for HIV: a systematic review. Health Technol Assess.,13(14):iii, ix-x, 1-60. https://doi.org/10.3310/hta13140

Cardo, Denise, Culver DH, Ciesielski CA, et al. (1997). A Case-Control study of HIV seroconversion in health care workers after percutaneous exposure. N Engl J Med.,337:1485-1490.

https://doi.org/10.1056/NEJM199711203372101

CA SB-159, §4052 (2019). HIV: Preexposure and Postexposure Prophylaxis.

https://leginfo.legislature.ca.gov/faces/billTextClient.xhtml? bill_id=201920200SB159. Accessed 14 July 2020

Centers for Disease Control and Prevention (CDC). (June 2020). HIV in the United States and Dependent Areas. Retrieved 21 July 2020 from

https://www.cdc.gov/hiv/pdf/statistics/overview/cdc-hivus-ataglance.pdf

Centers for Disease Control and Prevention (CDC). (June 10, 2020). Let's Stop HIV Together: Stand Together Against HIV Stigma. Retrieved 14 July 2020 from

https://www.cdc.gov/stophivtogether/hivstigma/index.html

Centers for Disease Control and Prevention (CDC). (June 4, 2020). PrEP. Retrieved 14 July 2020 from https://www.cdc.gov/hiv/basics/prep.html

Centers for Disease Control and Prevention (CDC). (October 29, 2019). Preventing New HIV Infections: Guidelines. Retrieved 15 July 2020 from CDC.gov.

https://www.cdc.gov/hiv/guidelines/preventing.html

Centers for Disease Control and Prevention (CDC). Updated Guidelines for Antiretroviral Postexposure Prophylaxis After Sexual, Injection Drug Use, or Other Non-occupational Exposure to HIV- United States, 2016. Retrieved 14 July 2020 from https://stacks.cdc.gov/view/cdc/38856
Choopanya K, Martin M, Suntharasamai P, et al. (2013). Antiretroviral prophylaxis for HIV infection in injecting drug users in Bangkok, Thailand (the Bangkok Tenofovir Study): a randomised, double-blind, placebo-controlled phase 3 trial. Lancet.,381(9883):2083-2090.

https://doi.org/10.1016/S0140-6736(13)61127-7

Food and Drug Administration (FDA). (October 3, 2019). FDA approves second drug to prevent HIV infection as part of ongoing efforts to end the HIV epidemic. Retrieved 14 July 2020 from https://www.fda.gov/news-events/pressannouncements/fda-approves-second-drug-prevent-hivinfection-part-ongoing-efforts-end-hiv-epidemic

Gilead Advancing Access ${ }^{\circledR}$ program. Gilead's Advancing Access ${ }^{\circledR}$ Program is Here to Help You. Retrieved 14 July 2020 from https://www.gileadadvancingaccess.com/

Godin G, Bélanger-Gravel A, Eccles M, Grimshaw J. (2008). Healthcare professionals' intentions and behaviours: a systematic review of studies based on social cognitive theories. Implementation Sci.,3(1):36.

https://doi.org/10.1186/1748-5908-3-36

Grant RM, Lama JR, Anderson PL, et al. (2010). Pre-exposure Chemoprophylaxis for HIV Prevention in Men Who Have Sex with Men. N Engl J Med.,363(27):2587-2599.

https://doi.org/10.1056/NEJMoa1011205

Gregory, Nancy. (February 13, 2020). California Readies for Implementation of Historic Law Aimed at Curbing HIV. Retrieved 14 July 2020 from https://www.ashp.org:443/News/2020/02/13/CaliforniaReadies-for-Implementation-of-Historic-Law-Aimed-atCurbing-HIV

Grohskopf LA, Chillag KL, Gvetadze R, et al. (2013). Randomized trial of clinical safety of daily oral tenofovir disoproxil fumarate among HIV-uninfected men who have sex with men in the United States. J Acquir Immune Defic Syndr.,64(1):79-86.

https://doi.org/10.1097/QAI.0b013e31828ece33

Hosek SG, Siberry G, Bell M, et al. (2013). The acceptability and feasibility of an HIV pre-exposure prophylaxis (PrEP) trial with young men who have sex with men. J Acquir Immune Defic Syndr.,62(4):447-456.

https://doi.org/10.1097/QAl.0b013e3182801081

Irvine C, Egan KJ, Shubber Z, Van Rompay KKA, Beanland RL, Ford N. (2015). Efficacy of HIV postexposure prophylaxis: systematic review and meta-analysis of nonhuman primate studies. Clin Infect Dis.,60(suppl_3):S165-S169. https://doi.org/10.1093/cid/civ069

Kanny D, Jeffries IV W, Chapin-Bardales J, et al. (2017). Racial/ethnic disparities in HIV pre-exposure prophylaxis among men who have sex with men -23 urban areas, 2017. MMWR Morb Mortal Wkly Rep. 2019;68(37):6. https://doi.org/10.15585/mmwr.mm6837a2

Légaré F, Borduas F, Freitas A, et al. (2014). Development of a simple 12 -item theory-based instrument to assess the impact of continuing professional development on clinical behavioral intentions. PLoS ONE., 9(3):e91013. https://doi.org/10.1371/journal.pone.0091013 
Marrazzo JM, Ramjee G, Richardson BA, et al. (2015) Tenofovir-Based Preexposure Prophylaxis for HIV Infection among African Women. N Engl J Med., 372(6):509-518. https://doi.org/10.1056/NEJMoa1402269

Matyanga CMJ. The role of the pharmacist in pre-exposure prophylaxis. (2014). PP., 05(03):225-228. https://doi.org/10.4236/pp.2014.53029

Molina J-M, Capitant C, Spire B, et al. (2015). On-Demand Preexposure Prophylaxis in Men at High Risk for HIV-1 Infection. N Engl J Med.,373(23):2237-2246. https://doi.org/10.1056/NEJMoa1506273

Murnane PM, Celum C, Mugo N, et al. (2013). Efficacy of pre-exposure prophylaxis for HIV-1 prevention among highrisk heterosexuals: subgroup analyses from a randomized trial. AIDS. 2013; 27(13):2155-2160.

https://doi.org/10.1097/QAD.0b013e3283629037

New York City Department of Health and Mental Hygiene (NYCDOHMH) HIV Epidemiology Program. HIV Surveillance Annual Report, 2018. (November 2019). Retrieved 21 July 2020 from

https://www1.nyc.gov/assets/doh/downloads/pdf/dires/hiv -surveillance-annualreport2018.pdf

New York State Department of Health (NYSDOH). (September 2018). PEP 4 HIV Prevention: Pharmacy Emergency Post-Exposure Prophylaxis for HIV Prevention. Retrieved 15 July 2020 from https://www.health.ny.gov/publications/9874.pdf

New York State Education Department (NYSED). (February 28, 2017). NYS Pharmacy: FAQ: Limited (Intern) Permit. Retrieved 22 July 2020 from

http://www.op.nysed.gov/prof/pharm/pharminternpermit. htm\#

Patel RR, Mena L, Nunn A, et al. (2017). Impact of insurance coverage on utilization of pre-exposure prophylaxis for HIV prevention. PLoS ONE.,12(5):e0178737.

https://doi.org/10.1371/journal.pone.0178737

Peterson L, Taylor D, Roddy R, et al. (2007). Tenofovir Disoproxil Fumarate for Prevention of HIV Infection in Women: A Phase 2, Double-Blind, Randomized, PlaceboControlled Trial. PLoS Clin Trials.,2(5):e27.

https://doi.org/10.1371/journal.pctr.0020027

Przybyla SM, Parks K, Bleasdale J, Sawyer J, Morse D. (2019). Awareness, knowledge, and attitudes towards human immunodeficiency virus (HIV) pre-exposure prophylaxis (PrEP) among pharmacy students. Curr Pharm Teach Learn.,11(4):352-360.

https://doi.org/10.1016/j.cptl.2019.01.011

Scott JD, Abernathy KA, Diaz-Linares M, Graham KK, Lee JC. HIV clinical pharmacists - the US perspective. Farm Hosp., 2010;34(6):303-308.

https://doi.org/10.1016/j.farma.2010.07.001

Tanner MR. Pre-exposure Prophylaxis for Prevention of HIV Acquisition Among Adolescents: Clinical Considerations, 2020. (2020). MMWR Recomm Rep., 69(3): 1-12. https://doi.org/10.15585/mmwr.rr6903a1

The National Alliance of State and Territorial AIDS Directors (NASTAD). (November 2, 2018). Retrieved 14 July 2020 from https://www.nastad.org/prepcost-resources/prepassistance-programs

Thigpen MC, Kebaabetswe PM, Paxton LA, et al. (2012). Antiretroviral Preexposure Prophylaxis for Heterosexual HIV Transmission in Botswana. N Engl J Med.,367(5):423-434. https://doi.org/10.1056/NEJMoa1110711

Tseng A, Foisy M, Hughes CA, et al. (2012). Role of the pharmacist in caring for patients with HIV/AIDS: clinical practice guidelines. Can J Hosp Pharm.,65(2):125-145. https://doi.org/10.4212/cjhp.v65i2.1120

United States Department of Health and Human Services (DHHS). Ending the HIV Epidemic: Ready, Set, PrEP. Retrieved 14 July 2020 from https://www.getyourprep.com/

Unni EJ, Lian N, Kuykendall W. (2016). Understanding community pharmacist perceptions and knowledge about HIV pre-exposure prophylaxis (PrEP) therapy in a Mountain West state. J Am Pharm Assoc., 56(5):527-532.e1. https://doi.org/10.1016/j.japh.2016.05.004

Van Damme L, Corneli A, Ahmed K, et al. (2012). Preexposure Prophylaxis for HIV Infection among African Women. N Engl J Med., 367(5):411-422.

https://doi.org/10.1056/NEJMoa1202614

Young, T, Arens FJ, Kennedy GE, et al. (2007). Antiretroviral post-exposure prophylaxis (PEP) for occupational HIV exposure. Cochrane Database Syst Rev., Issue 1. Art. No.: CD002835.

https://doi.org/10.1002/14651858.CD002835.pub3 